\title{
The Double Position of Waiting for Godot
}

\author{
Ali Taghizadeh ${ }^{1} \&$ Gholamhossein Mahmoud Soltani ${ }^{2}$ \\ ${ }^{1}$ Assistant Professor at the English Department of Razi University of Kermanshah, Iran. \\ ORCID: Orchid.org/oooo-ooo3-3820-1468.Email: altaghee@zedat.fu-berlin.de. \\ ${ }^{2}$ PhD Candidate in English, Razi University,Iran. Email: gm.sultani@gmail.com
}

Received March 27, 2016; Revised July 24, 2016; Accepted July 07, 2016; Published August 18, 2016

\begin{abstract}
No way can one exaggerate the unique position possessed by Samuel Beckett and his seminal play Waiting for Godot on the stage and in the dramaturgy alike. Undoubtedly, nestled in the core of this work lies some working which has bestowed it with such roaring success. Beckett's play is an embodiment of the idea that binary oppositions are not more than conventions which therefore can be subverted to allow a wide gamut of unprivileged voices to find a leeway. Waiting for Godot is full of ambiguities and binary oppositions, just to name the extreme one, the concept of "waiting" and the implicit binary of "substance/form. Therefore, it can be read as a dramatization of how it neatly pits such hierarchies against the deconstructionist suspicion of the accepted binary items present in the Western philosophical tradition. Considering how much affinity Derrida himself has seen with Beckett, Waiting for Godot is a ground conducive to the concepts of deconstruction to be practiced.
\end{abstract}

Key Words: Deconstruction, Duality Ambiguity, Substance, Form, Incubation

\section{Introduction}

The main theme of Samuel Beckett's Waiting for Godot is a familiar yet quite unknowable one. His play causes in the reader an acute feeling of sweet anxiety, the anxiety of confrontation with a waiting which is at the same time both familiar and unknowable. So, as long as we human beings have something to wait for, this play and its criticism are there to stay with us. The magnitude of this work is perhaps something upon which there is consensus among the readers while there is also an ever-altering kaleidoscope of points about it with degrees of disagreement. Therefore, (c) AesthetixMS 2016. This Open Access article is published under a Creative Commons Attribution Non-Commercial 4.0 International License (http://creativecommons.org/licenses/by-nc/4.o/), which permits non-commercial re-use, distribution, and reproduction in any medium, provided the original work is properly cited. For citation use the DOI. For commercial re-use, please contact editor@rupkatha.com. 
probing questions arise as to how this condition comes to be. What is there in the core of this play that makes it so ironically both immune and prone to various forms of categorically irreconcilable interpretations? What are the main binary oppositions subverted in it, and how does this relate to the philosophical lineage belonging to pre-Deconstruction era? More interestingly, it seems that having fostered a deconstructive mode of thinking, Waiting for Godot is a yardstick for measuring the distortion of the stabilized and classically accepted norms and notions.

This paper argues that Waiting for Godot's doubleness, ambiguity, and ambigram-like condition renders it simultaneously immune and prone to various, perhaps opposite, interpretations. In other words, it not only apparently fosters the conviction that sign is more than a one-way avenue, it also displays this paradigm in all its aspects and obsessions with dualities. As a play of significations, it portrays a dream in which a topsy-turvy world is as ethereal or incredible as the normalized one, and waiting in it is more of the nature of an act of incubation the result of which could be either a crack in the shell of life, or an eternal silence inside the shell which is a guarantee of death. Deridean deconstruction has most probably delved as deep as possible in the idea of ambiguities and oppositions, and since Derrida himself has assumed such a double position towards Beckett, it seems fitting that the double position of his play be critically analyzed in this study.

\section{Discussion}

\section{The Double Position of Waiting for Godot}

In Derek Attridge's 1989 interview with Derrida (Bennington, 1992), when the course of the interview takes a propitious course to venture two questions regarding Beckett, the way Derrida fashions his responses is by all means worth contemplation. The first question zooms on the reason why he has observed a silence on Beckett. Derrida quickly wraps up his answer saying that he feels himself "very close...but also too close" to Beckett (p. 6o). But before he is deterred from his fleeting remark, a more loaded question is imposed on him: if Beckett's texts are, from his point of view, “'deconstructive” or "self-deconstructive"' (p. 61).

The second question reveals a tendency to imply that Beckettian texts could be both the parole and the langue for Derridean deconstruction. That is to say, his texts simultaneously speak the language of deconstruction and its metalanguage. In response, he mentions that "... the two possibilities are in the greatest possible proximity and competition." Although, obviously enough, Derrida choses to handle the question evasively, the reason why he assumes this stance is not so much the concern of the present study as the actual existence of the stance itself. In other words, this study will attempt to examine Waiting for Godot both as a meta-deconstructive-theory text (langue) and a deconstructively-constructed text (parole), and the possibility of this double approach has been tentatively acknowledged by Derrida himself. Admittedly, from among Beckett's 
plays Waiting for Godot is the most-talked-about one. Thus, the scope of this paper is limited to it. Hence, the double-position of this play as an outstanding specimen of his oeuvre needs firstly to be further explored.

From the eye of Derrida, Deconstruction wants to displace the complex systems of Western intellectual hierarchies via "a double gesture, a double writing, a writing that is in and of itself multiple..., a double science" (1981, p. 41). It is a general strategy which works, among other things, for the cancellation of the binary oppositions (such as speech/writing) which Western philosophy has taken use of since the classical times. Thus, in the present study this doubleness, inherent as it is in the core of deconstructive strategy, is taken as a point of departure. As distinguished from and contesting such binaries and hierarchies by virtue of its conflating sides, this doubleness, that is, this policy of "both $X$ and $Y$ " (rather than the policy of "either $X$ or $Y$ ") is incorporated in the heart of Beckett's play in both textual and theatrical senses. However, before we further this point in a case-based manner, we should talk a bit about how this doubleness opposes to binary oppositions.

According to Derrida, the Western thought from the classical times has been revolving around the concept of centres (Powell, 200o, p. 21). In each binary opposition, such as dark/light or nature/culture, there are two terms (elements) one of which is traditionally privileged over the other. This means that the term which comes to be privileged necessarily entails the inferiority of the other one - hence the "either ... or" logic is imposed on the mind of the reader. In the binary presence/absence for instance, "presence" is the privileged term, and not only it is privileged, but it also excludes the inferior term, "absence", or pushes it aside. Therefore, whatever indicates presence enjoys the appointment to the prevalent position while that which fails to assert its presence is always overshadowed and dwarfed.

Inherent in Waiting for Godot is a duality (or an ambiguity) which allows for various readings. These readings can exist side by side without being mutually exclusive. Were Beckett's text revolving around a single centre whatever, it would undoubtedly find a way to marginalize any other possibility. So, one can understand why Paul Stewart argues that every study of Beckett seems to be an attempt to find "temporary accommodations with Beckett's texts" (2006, p. 10). The role of these temporary accommodations is analogous to that of a staircase landing where we are provided with relief from the anxiety of what is incessantly possible yet undecidable. As Jim Powell paraphrases Derrida, it is out of anxiety that we try to create new centres all the time and thus marginalize other centres (p. 29). Therefore, due to the role of a perfectly rich ambiguity in Beckett's play, the present research finds it well conducive to such interpretive analyses.

\section{A Reading for the Privilege of Presence}

We can address a number of critical approaches to Waiting for Godot with rather similar outcomes. One approach is reading it for its gnosticism, which is a teleological reading. Chris Ackerly's 
"'Perfection is not of this World': Beckett and Mysticism" (2004) is a teleological reading. In Ackerly's study, the messenger boy's appearance at the end of the two acts of the play at a moment when Beckett's audience may surmise that "Godot is an illusion" (p. 46), his appearance is interpreted as the introduction of light into darkness which saves the audience from the thrall of nihilism. For Ackerly, Beckett's fascination with dualism is indicative of the influence of Alexandrian neo-Platonism which is concerned with the conflict between opposites. However, what is of paramount importance here is the way Ackerly contests darkness with light and privileges the latter over the former.

A second approach to this play is that of Deirce Bair who works for underscoring "recognition" in Beckett's work. Bair maintains that Beckett's waiting for the recognition of his novels and for their acceptance into the canon was the main drive which oriented him towards drama - or more specifically speaking, towards Waiting for Godot. Therefore, there is the role in the play of the binary opposition "recognition/obscurity" and the play of its terms as an emblem of recognition.

In a like manner, in a thought-provoking study Elinor Fuchs has taken to identify the features of an Aristotelian tragedy in Waiting for Godot. At the end of her study, Fuchs argues that the Aristotelian elements of recognition, namely "reversal," "anagnorisis," and "pathos" are waiting to be born in the play; yet in the same manner, and like waiting itself in Beckett's play, they are never actualised. However, Fuchs' major focus is anognorisis, the excruciating expectation of the characters, which yet is never actualised. Needless to say, Fuchs thereby offers recognition a centrality which is made to fit in with the Aristotelian drama in a procrustean fashion.

However, the purpose of this paper is other than to find fault with these (kinds of) readings. It is to examine the way in which they are viable and tenable along with readings of a totally different nature as examined hereafter.

\section{A Reading for the Unprivileged}

Other critics, who have taken a different stance on Beckett's play, have allowed the autonomous singularities (in a Deleuzian/Guattarian sense) of it to reflect the high-modernist/postmodernist uncertainties and undecidabilities. Garin Gawd's work is a fitting turn, for it moves along the line of argument that has so far been initiated as the concept of recognition. Gawd studies the concept of "Abstract Machines" by the aforementioned thinkers with regard to the works of Beckett, and expounds that similar to other "Abstract Machines," the Beckettian machine is one of "becoming" but not of "being" (2007, p. 16). In Waiting for Godot there is a becoming process at work which cannot be reduced to being by recognition.

Yet, James H. Reid has adopted a different approach to this play, for he has perfectly managed to display the affinities between the postmodern space of Fredric Jameson and waiting for 
recognition in Godot. Explaining Jameson's argument, Reid maintains that there are means of filling the time, hobbies as such, while we are waiting for an unimaginable new mode of representation to enable us to grasp or recognise our status as individuals as well as collective subjects (1993, p. 79). Characters in Godot obviously indulge themselves in game-playing in order to fill the time as they wait to become able to introduce meaning to their conditions by establishing links with Godot who/which is simultaneously benevolent and malevolent but at any rate as their only way out. These examples make it clear that doubleness, that is, the ambiguity of "becoming" rather than the certainty of "being", is put forth in the paly while it shows no attempt to fix itself to a centre of any kind. In the remaining part, this article will attempt to examine some of the most remarkable cases in Beckett's play where it is uniquely fascinated with this feature of ambiguity.

\section{"Waiting for Godot" or the Godot of Waiting?}

The "Waiting" in the title of Beckett's play is the crystallization of an existential ambiguity. A logically fundamental tenet is that the existence of an object precedes waiting for it. This is to mean that in order for waiting to be directed towards an object, it must have already come into existence (as an origin). In the process of causation, this tenet occupies an originary position, and whatever comes after it is taken for secondary or derivative (Culler, 1985, p. 87).

However, Culler also argues that in the world of our mental experiences the cause (of something) is brought into existence by an effect and through what is known as metalepsis, which is the substitution of the cause for the effect (p. 86). To exemplify this, we may say that it is the "pin" which creates the "pain" in our body; but it is also equally true if we say it is the "pain" that causes the "pin" to originate or take shape in our mind. The outcome of such a radical decentering policy is leaving both the cause and the effect divested of any originary position and thus rendering the traditional hierarchy of causation no longer as capable to operate.

In the waiting/Godot binary, waiting can be as much originary as Godot. To say it another way, Godot himself/itself may be taken as the product of waiting: an object which comes into existence only because its existence is presumed, is a posteriori. Nevertheless, it can also be considered as an a priori, that is, the origin and the cause of waiting which would prove it to be a meaningful and productive activity. This simultaneous existence of the opposites is made possible in the first place by the overarching ambiguity in the nature of waiting. The waiting condition which is highlighted in Beckett's play, encompasses a scope as vast as that of the whole life, and in so doing allows for every kind of interpretation that goes along either direction. Speaking metaphorically, waiting in Beckett's play is naturally akin to a period of possible incubation, a period in which an egg either hatches or does not get hatched, that is, a period when expectations and speculations regarding either possibility hold true. Waiting as a sign, which is comprised of both a signifier and a signified, has incorporated the undecidable opposition of birth/death into its 
signified. In this binary, the privileged term is classically "birth", but it seems that in subsequent periods when the established culture is typically presence-dominated, "birth" has taken many different names, many different centres, which allude to presence - that is, it has become a metaphor or metonymy of those cultural elements which embody presence, such as a messiah, or a redemptive ideology. As Derrida explains it, “... these metaphors and metonymies... all the names related to fundamentals, to principles, or to the center have always designated an invariable presence-eidos ... (essence, existence, substance, subject)...”(2002, p. 353).

Going back to the idea of metalepsis, it is suggested that we can take Godot as the product of waiting. We can see it/him not as the cause of waiting, but as the effect of it. In a like manner as with the sign of incubation (which was metaphorically substituted for the action of waiting), Godot as a sign is dissected into its constituent parts: a signifier and a signified. As it is identifiable, the signified for Godot is a shared signified with the incubation, namely the undecidable opposition of birth/death or presence/absence. By the same token, Godot can be seen to metaphorically represent any binary opposition in which one term is traditionally privileged over the other one. Catherine Malabou illustrates how a metaphor is like a missionary, a representative sent on an "adventure of representation" between the oppositions (2004, p. 40). In other words, a metaphor is a sign which is sent from the metaphorical domain to the literal in the opposition of literal/metaphorical and due to the fact that an originary position is appointed to the traditionally central term of the literal while the metaphorical is taken for "derivative" (Derrida, 1997, p. 7). Considering the opposition in birth/death or presence/absence, which was earlier argued as the constituent parts of the signified of waiting, the privileged term is birth, presence. Yet, in the opposition of object(Godot)/waiting, it is, traditionally speaking, considered derivative.

In this tradition, Godot is the object towards which waiting is directed, and as the adventure of representation would entail, it moves towards this originary object. This, however, is a case of metalepsis, as mentioned earlier.

Godot is a metaphor whose referent is not in possession of centrality, origin, or stability. Notwithstanding, its referent, which is waiting (or incubation, metaphorically), is at best trapped in an unending language game which may only be frozen in order to supply a temporary relief from anxiety. Godot, whose existence is confirmed by nothing more the messenger(s) whose unreliability is often hinted at, never comes however is always only meant to come, however is always on the verge of coming. Nevertheless, the venue of incubation (waiting) is, according to Beckett's text, "same place". This locational fixedness of incubation (waiting) can be taken to verify the argument that the subverted hierarchy is well-justified. The term which is on the move, in line with what Malabou has written about the adventure of representation, towards the centre, is Godot. He speaks through a messenger boy as a connection to the place of the rendezvous, but a timid and unreliable one, an arbitrary relation. The question is: What is there for Beckett's reader 
to believe that Godot really exists but the reality of waiting as the $a$ priori? Can the reader take that the messenger is from an existing Mr. Godot? The significance of this mode of reading is not that it subverts the hierarchy but that it foregrounds a simultaneity of opposite possibilities without excluding either of them.

\begin{abstract}
'Ah'piphany
In Waiting for Godot, characters are taken over by their immediate actions and momentary occupations to an extent that the provisional activity done to overcome the anxiety of waiting elbows the major (in)action out of the way and finds centrality. This subversion of the hierarchy of the "provisional/major" is given a significant role in the play. Reid argues that Vladimir and Estragon engage themselves in a variety of activities while waiting in order to waste their time without guilt and involve themselves in a sort of pseudo-productive activity (1993, p. 79). It seems that they have a thing about filling in (the gap of) the time they are waiting with some kind of hobby so that their anxiety gets mitigated.

However, it is not only Didi and Gogo who are waiting, but the reader also, or the audience, who is waiting for the ever-absent Godot to show up. As Hugh Kenner says, in Beckett's play "[t]o wait; and to make the audience share the waiting; and to explicate the quality of the waiting" is filled with "beautifully symmetrical structures" (1973, p. 33). Therefore, and in line with Kenner's argument, all of what Beckett's characters do to pass their hollow time is fashioned structurally as well as symmetrically. Yet, after an examination of their array of pastime it gets revealed that they are ruled by form but not filled with meaning. As mentioned above, these forms are "beautifully symmetrical structures." Yet such structures are not void of meaning, because they take foregrounding functions. For instance, in Act II there is an exemplary exchange between Vladimir and Estragon, as in the following:
\end{abstract}

ESTRAGON: In the meantime let us try and converse calmly, since we are incapable of keeping silent.

VLADIMIR: You're right, we're inexhaustible.

ESTRAGON: It's so we won't think.

VLADIMIR: We have that excuse.

ESTRAGON: It's so we won't hear.

VLADIMIR: We have our reasons.

ESTRAGON: All the dead voices.

VLADIMIR: They make a noise like wings.

ESTRAGON: Like leaves.

VLADIMIR: Like sand. 
ESTRAGON: Like leaves.

Silence.

VLADIMIR: They make a noise like feathers.

ESTRAGON: Like leaves.

VLADIMIR: Likes ashes.

ESTRAGON: What do we do now?

VLADIMIR: Wait for Godot.

ESTRAGON: Ah!

In this abridged exchange, which is originally in more than thirty lines, we see Beckett's characters calmly conversing in a language which is somehow both rhythmical and figurative. They are yet so carried away in the form of their activity that Estragon, the less metaphoric speaker, has a hard time recalling the main reason why they are on that country road. This structure, which apparently wants to excite Beckett's characters to do something for a solution to a messy condition, is often punctuated with silences, ends in initial stages, and waiting gaps. So, in the course of their dramatic waiting their situation gets more violent, because as Okamuro claims, the "four characters - Vladimir, Estragon, Pozzo, and Lucky - in a sense spiral towards nothingness around the core of an absent fifth, Godot, who never appears" (2004, p. 93). This spiral pattern of waiting for a guy who will never come, but which is yet predominantly form-governed, incites us to reconsider the form of Beckkett's work. For example, when in the exchange quoted above Vladimir complains that for the talking dead "to have lived is not enough," in reply to his complain Estragon says "they have to talk about it," by which it is likely that Beckett means they have to narrativize their lives. Roland Barthes and Lionel Duisit maintain that this function "constantly substitutes meaning for the pure and simple facsimile of narrative events" (1975, p. 267). In other words, narrativizing is a cultural strategy for filling in the gap of the events or forms with meaning. Thus, when events are narrated, meaning seeps into them, and so the form which they possess is filled with sense, with substance.

This could be seen as the subversion of another classical binary: meaning/form. In Positions Derrida mentions the binary opposition of form/substance for the appreciation of which we here need briefly to discuss the Heideggerian idea of Being and its critique by Derrida himself. The German philosopher proposes that Western metaphysics since classical times has wrongly treated the question of Being and has therefore resulted in "forgetfulness of Being" (200o, p. 18). He contends that for Plato and Aristotle there is an underlying essence that imposes form onto the surface appearances and thus unites the essence to the form (Lack, 2014, p. 11). There exists an essence for, say Tree, which is the Ideal or Original Tree, and also there exist trees as the surface appearances of the Ideal Tree. This is the substance "Tree" which imposes form on its copies or duplicates, which are the very trees available to us. For another example, there is a substance or 
ideal dog and there are dogs which are governed by that substance. Therefore, Plato and Aristotle were of the opinion that the substance was shaped into its representative forms by way of either internal structures that led them to their telos or by external forces that helped them get united behind the substance (p. 11). This inbuilt character in the Ideal Tree leads it to the point where it is substantiated as trees. In other words, the potential contains the feature that leads it to a reality, to a form.

\section{A Lineage of Substance/Form Hierarchy}

However, for Heidegger the connection between substance and form is a question which Western metaphysics has seemingly forgotten. Since Plato, in Western Metaphysical tradition Being has been converted into a Form or substance endowed with a static meaning and with "ultimate truth" (Lack, 2004, p. 9). Yet Heidegger sees a dynamic process working between the substance and the surface which is filled with possibilities. As he explains, among the pre-Socratic philosophers who used to understand Being as an emerging power, there was a belief in Phusis which was a source of both presence and absence and which is therefore a dynamic process (10). This dynamic process simultaneously differentiates the substance and the surface appearances and keeps them together. Thus, there is a space between the substance and the forms of it which is the space of dynamic differences and which Western metaphysics has been waiting long to bridge and cover. The space about which Heidegger speaks, that is, the space of ontological differences, is similar to the arbitrary relation between the signified and the signifier which is based on referentiality and which is therefore ruled by a tendency to assign a centre in order to make it meaningful. This is exactly what Derrida criticizes in Of Grammatology when he affirms that Heidegger was wrong when he claimed that "a sign must be a sign of something and that language needs this referentiality to be capable of expressing truths" (Couzens, 1979, p. 228). As discussed earlier, this very refrentiality, the process via which a derivative is referred to its origin, also holds true for the very principal question of the connection between form and substance in which the substance, essence, or the transcend Form is privileged over the surface appearance, the form, the signifier. Therefore, one reason why speech has been privileged to writing is that speech is, due to its presence, more closely connected to and identified with the substance. In Of Grammatology Derrida quotes Ferdinand de Saussure saying "Language and writing are two distinct systems of signs; the second exists for the sole purpose of representing the first" (1997, p. 30). He then argues that Saussure has actually been following the Aristotelian definition of writing and therefore that not much has changed since. In this tradition, it is "the spoken form alone" which constitutes the "linguistic object," and the written form is therefore just for the representation of speech as a direct conduit for the entirety of a mental experience. Therefore, writing is referential and is just a derivative to speech. 


\section{Substance: neither Godot nor Waiting}

Lucky's monologue is an exemplary case of the game-like activities in Beckett's play as pure forms to substitute for the formless time of waiting and to mitigate its torment. Gibson (2010) contends that Lucky's monologue in the play is "majestically nonsensical" but so "compulsive" in form that "in the end, the other characters have violently to floor him" (p. 41). Yet, what is missing from these Lucky's lines that disappoints the audience and instigates violence?

Derrida maintains that a desire for presence, or in other words, for sense or meaning, is doomed to remain unfulfilled for there is nothing as such (Gendron, 2004, p. 27). This is to say that the link between the form (writing in the case of Beckett's play) and the substance (the present meaning) is intrinsically impossible to establish. So, taken as a sign, the utterances in the play's time-fillers fail to establish the supposed link between themselves and the essence - or rather they fail to appoint themselves as direct conduits for the 'originary' mental experiences to pour into the void which is created by the inaction of waiting. Form, the written form in the case of Beckett's play, has been cut off from the substance and thus can become so compulsive in in that it may distract the characters from their main purpose which is waiting for Godot. They, however, go back to their "waiting" and remind themselves of it. The three final lines of the play take a revealing role in this futile practice. This exchange is repeated ten times in the play while it occurs three times in the first act and seven times in the second. This kind of exchange usually occurs when there is a distraction of the nature of the mentioned time-fillers and Estragon needs to be reminded of their purpose of being on that country road.

However, it is Vladimir who is meant to answer the ubiquitous question "What do we do now?" with "Wait for Godot." Returning, then, to our main argument, the reason why Estragon should be reminded of the purpose is that between the form they are involved in, that is their appearance on the country road, and the essence of it which is "Waiting for Godot" there is no intrinsic connection. If we take all they do as animated by their state of waiting, then why do they need to be reminded of it?

Estragon's monosyllabic answer "Ah!" is mostly accompanied by stage instructions which signify a state of despair. This is a moment of epiphany in the play, a moment of recognition for Estragon or rather for the whole play. It sets the spiral pattern mentioned earlier in train again which is to lead to a whole vacancy, a pattern in which everything ends in Waiting for Godot or rather in an epiphanic "Ah!" This epiphany, or rather "Ah"piphany, is indicative of the fact that the link between the form and the substance is but transiently and feebly established and passively and pensively acknowledged.

This too leads to a kind of ambiguity embodied in the form of Godot. Godot itself is a form whose connection to substance is threatened by the fact that its presence is neither verified nor rejected but that which is becoming more distant. So Godot is a state of in-between-ness, and 
borrowing from Derrida, it is a "hymen" which is "neither identity nor difference, neither veil nor unveiling" (1981, p. 41). This stance is surely against the general acceptance of Waiting for Godot, and as Alain Robbe-Grillet has pointed out, as a representative of the Heideggerean conceptualization of the human condition as Dasein or "being-there" (1965, p. 119). This is to say that in Heideggerean term Dasein is that through which being comes forth and finds meaning. Therefore, in their "being-there" Vladimir and Estragon, who do nothing but wait, basically represent the modern human condition. To say it another way, Dasein is the pure presence which is yet challenged by Derrida. As it is shaped by Beckett, Godot is no Dasein, for Dasein is that which allows for presence to actualize, but Godot's presence is even further questioned as the play progresses. Godot is that which through its doubleness and ambiguity allows for the form (writing) to subvert substance and for the hierarchy to be turned upside-down.

In $O f$ Grammatology we read that "writing does not have a different origin from that of speech: need and distance. Thus it continues the language of action. But it is at the moment that the social distance, which had led gesture to speech, increases to the point of becoming absence, that writing becomes necessary" (Derrida, 1997, p. 281). These lines play a much revealing role in the way Godot is seen in the cosmos of deconstruction. Godot's double position as absent and present, or as neither absent nor present, is rooted in its distance. It is distant from Vladimir and Estragon, a distance which has rendered it "inaudible" and "invisible" to use Derrida's terms. Even if some critics like Mary M. F. Massoud see Godot as having actually visited Vladimir and Estragon as Pozzo and Lucky, yet was not recognized (2010, p. 49), its very being unrecognized is evidence of its distance and that it has given rise to a further generation of form (writing).

Furthermore, the dual presence of the Boy as Godot's messenger is another case which verifies the distance and the undecidability that Godot has caused. Even the Boy, when asked about the colour of the beard of Godot, replies "I think it's white, Sir." This answer tentatively verifies not only Godot's ambiguity but also its inherent distance. This is to say that even the messenger, who is supposed to have first-hand information about Godot since he and his supposed brother work for him, does not know whether his beard is fair or black.

\section{Conclusion}

Duality, ambiguity, and doubleness show themselves in the form of binary oppositions of which the superiority of an item to the other is based on unfounded or absurd grounds. Samuel Beckett's Waiting for Godot displays the condition of such instability and/or undecidability, and thus allows for a huge influx of interpretations whenever these binary items swap places. This claim finds a firm footing in the way Heidegger revives the pre-Socratic philosophers' dynamic view of Phusis which simultaneously contains the opposites and thus all possibilities. When possibilities are available, and the space wherefrom they find realization is open and not covered over, a wider range 
of tastes and interpretations can connect to it. Since Waiting for Godot takes to shake the binaries and hierarchies to an extent which allows possibilities to exist and sustain simultaneously, and since the privileged and the unprivileged are equally defensible and justifiable in it, it is closer to a state of Phusis.

As a consequence, in comparison with other works of contemporary drama Beckett's play has appealed to a much larger readership and will probably do so for a longer period hereafter. Furthermore, the philosophical depth and nuances of this play lend a very versatile nature to it. Notwithstanding, this paper has selected a number of Derridean and Hiedeggerean concepts via which to shed light on its presented arguments about the play, and it comes to the conclusion that binary oppositions in it are artistically manipulated and thus it can be fruitfully approached in the light of Derridean deconstruction. For instance, its central idea of "waiting" is classically or better said Metaphysically seen as an act directed towards an object. That is, as seen by many critics, waiting in this play has an already-existent object, Godot, which is the target of interpretive attempts.

Added to the plausibility of this notion, there is an equally acceptable approach to this play which takes "waiting" as a Godot-creating force. Here is where Godot is apparently a derivative of "waiting". Godot is therefore not the initiator of waiting, which of course many critics have seen as such, but the product of it.

Moreover, Godot is the distance that necessitates writing, the distance which calls for intermediary elements to fill in it. Speaking metaphorically, this Godot is the pin that is created by pain, the pain and anxiety of having to wait but at the same time not knowing what to wait for or how to wait. This, and the other cases discussed heretofore show that Waiting for Godot possesses or offers grounds for various interpretations to hold true and it is because it does not pertain to a single ultimate truth. In this text Beckett has delineated that the way we perceive the one-way track of signs is a total illusion and thus its opposite too is always equally possible, conceivable, justifiable, and perchance more beneficial, since it opens up a field of possibilities which has so far been obscured on the basis of accepted paradigms.

\section{References}

Ackerly, Chris. (2004). Perfection Is Not of This World: Samuel Beckett and Mysticism. Mystics Quarterly, 30 (1-2), pp. 28-55.

Barthes, Roland and Lionel Duisit. (1975). An Introduction to the Structuralist Analysis of Narrative. New Literary History. 6 (2), pp. 237-272.

Couzens Hoy, David. (1979). Forgetting the Text: Derrida's Critique of Heidegger. Boundary 2, 8 (1), pp. 223236. 
Culler, Jonathan. (1985). On Deconstruction: Theory and Criticism after Structuralism. New York: Cornell University Press.

Derrida, Jacques. (1981). Positions. (translated and annotated by Allan Bass). Chicago: Chicago UP.

---. (1997). Of Grammatology. (translated by Gayatri Chakravorty Spivak). Baltimore: Johns Hopkins UP.

---. (2002). Writing and Difference. (translated with an introduction and additional notes, by Alan Bass). London: Routledge Classics.

---. (1992). This Strange Institution Called Literature: An Interview with Jacques Derrida. (pp. 33-75). Acts of Literature. (edited by Derek Attridge, translated by Geoffrey Bennington and Rachel Bowlby). London: Routledge.

Gawd, Garin. (2007). Abstract Machines: Samuel Beckett and Philosophy after Deleuze and Guattari. Netherlands: Editions Rodopi B.V.

Gendron, Sarah. (2004). 'The Death of a Dynasty' Presence in Drama and Theory: Samuel Beckett and Jacques Derrida. Journal of Dramatic Theory and Criticism, 18 (2), pp. 21-40.

Gibson, Andrew. (2010). Samuel Beckett. London: Reaktion Books Ltd.

Heidegger, Martin. (200o). Introduction to Metaphysics. (translated by Gregory Fried and Richard Polt). New Haven: Yale UP.

Kenner, Hugh. (1973). A Reader's Guide to Samuel Beckett. New York: Farrar, Straus.

Lack, Anthony. (2014). Martin Heidegger on Technology, Ecology, and the Arts. New York: Palgrave Macmillan.

Malabou, Catherine and Jacques Derrida. (2004). Counterpath: Travelling with Jacques Derrida. (translated by David Willis). Stanford: Stanford UP.

Massoud M.F., Mary. (2010). Beckett's Godot: Nietzsche Defied. Irish University Review, 40 (2), pp. 42-53.

Okamuro, Minako. (2004). Alchemical Dances in Beckett and Yeats. Samuel Beckett Today, 14, pp. 87-103.

Powell, Jim. (2000). Derrida for Beginners. London: Orient Longman Ltd.

Reid, James H. (1993). Allegorizing Jameson's Postmodernist Space: Waiting for Godot. Romanic Review, 84 (1), pp. 77-96.

Robbe-Grillet, Alain. (1965). Samuel Beckett, or Presence on the Stage. (pp. 111-126). For a New Novel: Essays on Fiction (translated by Richard Howard). Illinois: Northeastern UP.

Stewart, Paul. (2006). Zone of Evaporation: Samuel Beckett’s Disjunctions. Netherlands: Editions Rodopi B.V. 